\section{Infectious Disease Surveillance}

N.M. M'ikanatha, R. Lynfield, C.A. Van Beneden, H. de Valk, editors

Blackwell Publishing, Malden, MA, USA, 2007

ISBN-13: 978-1-4051-4266-3

Pages: 560; Price: US \$195.00

This book devotes chapters to the usual infectious disease suspects and surveillance concepts and systems. I will not go into details of its contents and glowing attributes; the publisher (www.blackwellpublishing.com/ book.asp?ref=9781405142663) and reviewers $(1,2)$ have done a good job on this. Instead, I conducted a simple review to try and answer the following question: compared with a free Internet search, is purchase of a \$195.00 book worth it? My hypothesis was that by entering the title of a chapter from the book in a search engine, one could find comparable content within the first 20 results (links) returned.

\section{Methods}

After selecting the chapter that corresponded with every 50th page of the book, I visually scanned that chapter for scope and content. Then I performed a Google search using the chapter title and ranked the level of congruence between the topics in the book chapter and the topics at the Internet links as follows: fully comparable, $\geq 1$ links covered most $(\approx \% 75)$ topics in the chapter; partially comparable, $\geq 1$ links covered many $(\approx 50 \%)$ of the topics; and not comparable, all links reviewed (up to 20) covered $<50 \%$ of the topics. Each search result link was reviewed in successive order up to 20 results until $\geq 1$ enabled a ranking of fully comparable. Links that led to other links would be followed only 1 level deep. Links that required log-in or payment or that reproduced a complete chapter were excluded.

\section{Results}

Of the 40 chapters, 10 were reviewed. Of these, 4 were ranked as fully comparable, 4 as partially comparable, and 2 as not comparable.

For example, a rating of fully comparable was given for the chapter "Public Health Surveillance for Vaccine Adverse Events." After 6 links were reviewed, 2 were found to provide similar information to that of the book chapter. A rating of partially comparable was given for "The Netherlands' Infectious Diseases Surveillance Information System." Of 20 links reviewed, several contained related information, but none were as complete as the book chapter and some provided a more global view. A rating of not comparable was given for "Use of Molecular Epidemiology in Infectious Disease Surveillance" after a review of all 20 links. Although several links provided information on the topic, none provided as organized and clear a summary as did the book chapter.

\section{Discussion}

Extrapolation of these findings to all 40 chapters is difficult because of variation in topics and titles, and extrapolation to other research areas may depend on the proportion of information published without restrictions, i.e., without requesting registration, passwords, or money. Overall, a considerable amount of Internet information was obtained for most chapters evaluated, although usually $>1$ link had to be reviewed. The convenience of being able to read at one's own pace a book containing the full gamut and organized presentation of such subject matter must be weighed against the timeliness and cost differential of an Internet search.

\section{Conclusions}

This book is a good value for public health students and professionals frequently involved in surveillance and surveillance issues. It is not neces- sarily a good value for those with only infrequent needs to find information quickly or to find up-to-date information on several surveillance topics.

\section{Marc A. Strassburg}

Author affiliations: Los Angeles County Department of Public Health, Los Angeles, California, USA; University of California, Los Angeles, California, USA; and TUI University, Cypress, California, USA

DOI: 10.3201/eid1604.090584

\section{References}

1. DeMaria A Jr. Infectious disease surveillance. N Engl J Med. 2008;358:1413-4

2. Grassly NC. Infectious disease surveillance. JAMA. 2008:300:1591-2.

Address for correspondence: Marc A. Strassburg, Los Angeles County Web Informatics, Los Angeles County Department of Public Health, 313 N. Figueroa St, Rm 127, Los Angeles, CA 90012, USA; email: mstrassburg@ph.lacounty. gov

\section{Denialism: How Irrational Thinking Hinders Scientific Progress, Harms the Planet, and Threatens Our Lives}

\section{Michael Specter}

Penguin Press, New York, NY, USA, 2009

ISBN: 1594202303

Pages: 304; Price: US \$27.95

Vaccines remain one of our most critical public health interventions, yet an increasingly vocal group of antivaccinationists call vaccines toxic and attribute numerous conditions, such as autism, to vaccination despite 
evidence to the contrary. Former Playboy model Jenny McCarthy is viewed as a respected source of information, whereas pediatric infectious diseases researcher Paul Offit receives death threats for his scientific contributions. Journalist Michael Specter describes this phenomenon in Denialism: How Irrational Thinking Hinders Scientific Progress, Harms the Planet, and Threatens Our Lives.

Spector defines denialism as "denial writ large - when an entire segment of society, often struggling with the trauma of change, turns away from reality in favor of a more comfortable lie." Denialism describes this rejection of fact-based reality in 6 different areas related to health and medicine, beginning with the mistrust of pharmaceutical companies and their products. $\mathrm{He}$ also examines the dismissal of racial differences in medical research, the organic food movement as a form of denialism, and the obsession with vitamins and complementary alternative medicine despite evidence that these modalities do not work or may even be harmful. He ends with a look to the future: creation of life itself and why we must overcome denialism and embrace change to continue advancing as a society or risk the survival of our species.

This book is sure to cause some controversy. In many circles, the term denialism is still linked to rejection of the Holocaust, and any implica- tion that parents' refusal of vaccination or the philosophy of choosing organic-only food is akin to dismissal of one of humanity's great atrocities surely will make some readers dismiss Specter's arguments. Likewise, although Specter supports industry, he is pragmatic and does not put himself in a cheerleader role, instead acknowledging corporate culpability in driving and perpetuating denialism: "Corporations, wrapping themselves in the mantle of progress but all too often propelled by greed, have done more than religion or even Luddism to inflame denialists and raise doubts about the objectivity of science." Specter realizes that industry, and scientists, have lost the public's trust, and this broken relationship needs to be fixed through additional communication to the public by scientists and science writers, open debates about the future of scientific progress and implications of emerging technologies, and improvements in education.

Persons picking up this book may be surprised by the lack of discussion about some prominent topics of science denialism, including evolution and global warming. Likewise, Specter does not discuss HIV/AIDS denial, a topic he has covered previously in The New Yorker (1). Referring to the latter, Specter notes that Holocaust and HIV/AIDS denialists are “... intensively destructive - even homicidalbut they don't represent conventional thought and they never will. This new kind of denialism is less sinister but more pervasive than that." Furthermore, the types of denialism Specter describes cut across political and religious divisions to combine fear and uncertainty in a manner that makes them contagious. Indeed, a central tenet of denialism is that "fear is more infectious than any virus" and, like infection, needs to be addressed and, ideally, prevented through healthy skepticism.

Spector notes that "Denialism must be defeated. There is simply too much at stake to accept any other outcome." Its defeat is a tall order, but an imperative one if science is truly to be restored to its rightful place. Specter's book is a good starting place for any scientist or layman interested in delving into this phenomenon.

\section{Tara C. Smith}

Author affiliation: University of lowa, lowa City, lowa, USA

DOI: 10.3201/eid1604.091710

\section{Reference}

1. Specter M. Annals of science: the denialists. The New Yorker. 2007 Mar 12:32.

Address for correspondence: Tara C. Smith, Department of Epidemiology, Center for Emerging Infectious Diseases, University of Iowa, 200 Hawkins Dr, C21F GH, Iowa City, IA 52242,USA; email: tara-smith@uiowa.edu

\section{Errata-Vol. 16, No. 2}

The article Hendra Virus Outbreak with Novel Clinical Features, Australia ( $\mathrm{H}$. Field et al.) contained several errors related to specific case descriptions and spillover events. The article has been corrected online (www.cdc.gov/eid/content/16/2/238.htm).

The author list for the article Epidemiology of Cryptoccocus gattii, British Colombia, Canada, 1999-2007 (E. Galanis et al.) was incomplete. Authors were Eleni Galanis, Laura MacDougall, Sarah Kidd, Mohammad Morshed, and the British Columbia Cryptococcus gattii Working Group. Working Group members involved in this study were Patrick Doyle, John Galbraith, Linda Hoang, Pamela Kibsey, Min-Kuang Lee, Sultana Mithani, Marc Romney, and Diane Roscoe. The article has been corrected online (www.cdc.gov/eid/content/16/2/251.htm).

\section{Erratum-Vol. 16, No. 3}

The author list for the article Use of Avian Bornavirus Isolates to Induce Proventricular Dilatation Disease in Conures (P. Gray et al.) omitted W. Ian Lipkin. The article has been corrected online (www.cdc.gov/eid/content/16/3/473. htm). 